\title{
Skin Diseases in Patients with Primary Psychiatric Disorders
}

\author{
Paraskevi Mavrogiorgou1, Corinna Mersmann 1 , Gabriele Gerlach², Stephan Herpertz², and Georg Juckel ${ }^{1 凶}$ \\ 'Department of Psychiatry, Ruhr University Bochum, LWL-Universitätsklinikum, Bochum, Germany \\ ${ }^{2}$ Department of Psychotherapy and Preventive Medicine, Ruhr University Bochum, LWL-Universitätsklinikum, Bochum, Germany
}

\begin{abstract}
Objective The few psychodermatological studies of primary psychiatric populations so far suggest that parasitic-infectious skin diseases are the most common dermatological comorbidity in more than $70 \%$ of psychiatric patients, which should be studied here in a large data bank outside dermatological treatment facilities.
\end{abstract}

Methods In a descriptive-explorative and retrospective study, more than 17,000 patients with primary psychiatric disorders were examined to investigate dermatological comorbidities.

Results The proportion of patients with primary mental disorders and additional dermatological disease was $1.24 \%$ ( $n=212$ ). Here, psoriasis (35.4\%) and atopic dermatitis (22.6\%) were the most frequent dermatological diseases among these 212 patients. Infectiousparasitic skin diseases were present in $13.2 \%$ of comorbid patients. The most common mental disorder was a depressive illness, seen in $42.5 \%(\mathrm{n}=90)$ of patients.

Conclusion Our results confirmed the frequent association of depression with psoriasis and atopic dermatitis, indicating the need for the early detection and treatment of such comorbid patients. In contrast, psychiatric inpatients do not appear to suffer from predominantly infectious-parasitic dermatoses.

Psychiatry Investig 2020;17(2):157-162

Key Words Psychodermatology, Skin diseases, Psychiatric disorders, Depression.

\section{INTRODUCTION}

Both the skin and the central nervous system (CNS) are derived from ectoderm during embryogenesis; their resulting anatomical-functional relationship has long been known. Nevertheless, many aspects of this partially obvious connection are not fully understood. In particular, the complexity of the structure and the meticulous functions of both the skin and the CNS, but also the multiple interactions between them, complicate the investigation of pathological reactions and phenomena. This is reflected even in the rather poor state of studies with regard to the comorbid occurrence of mental disorders and skin diseases, although there are a number of publications which confirm an association between dermatoses and mental illness. In a multicentre study in 13 European countries, a close link be-

Received: July 31, 2019 Revised: November 19, 2019

Accepted: December 3, 2019

$\triangle$ Correspondence: Georg Juckel, $\mathrm{MD}, \mathrm{PhD}$

Department of Psychiatry, Ruhr University Bochum, LWL-University Hospital, Alexandrinenstr.1, Bochum 44791, Germany

Tel: +49-234-5077-1100, Fax: +49-234-5077-1109

E-mail: georg.juckel@rub.de

(c) This is an Open Access article distributed under the terms of the Creative Commons Attribution Non-Commercial License (https://creativecommons.org/licenses/bync/4.0) which permits unrestricted non-commercial use, distribution, and reproduction in any medium, provided the original work is properly cited. tween depression, anxiety disorders, and skin diseases was demonstrated on the basis of 3,635 dermatologically ill participants and a control group of 1,359 healthy individuals. ${ }^{1}$ In this study, depressive disorders ( $10.1 \%$ vs. $4.3 \%$ ) and anxiety disorders (17.2\% vs. $11.1 \%)$ were the most comorbid mental diseases in patients with primary psoriasis, atopic dermatitis, hands' eczema and ulcus cruris. ${ }^{1}$

Such investigations, alongside most of the published studies, were usually performed in dermatological or psychodermatological-psychosomatic treatment facilities, ${ }^{2-7}$ but rarely in psychiatric hospitals. ${ }^{89}$ However, the isolated findings from studies conducted in primary psychiatric populations suggest that infectious-parasitic dermatoses are the most common skin diseases in over $70 \%$ of patients with mental disorders. Researchers have discussed a possible explanation for this high comorbidity rate: the overall reduced physical condition of many mentally ill patients, which is associated with a reduced immune defense and thus increased susceptibility to infections of the skin. ${ }^{8,9}$

Even though, in spite of this understandable explanation, these findings suggest that most patients with mental illnesses (and especially patients with schizophrenia) are incapable of performing their day-to-day hygiene and health care respon- 
sibilities, this impression should also be subjected to a critical evaluation due to aspects of stigmatization, which are widespread concerning psychiatric patients.

The aim of our descriptive-exploratory, the retrospective data-based study was, therefore, to further examine patients with a primary mental disorder in regard to dermatological comorbidities.

\section{METHODS}

First, in order to collect data, all psychiatric cases (ICD-10: F00-F99) were identified from a total of 5,071 patients hospitalized at the Department of Psychiatry (LWL-University Hospital Bochum) between 1984 and 2006 who also had a skin disease (ICD-10: L00-L99) according to the medical records. Here, the criterion of comorbidity met $n=86$ patients.

In addition, a second total sample of 12,014 patients was selected from the annual electronic records, according to $\S 21$ KHEntG (Krankenhausentgeltgesetz), in the period between 2007 to 2015 under the inclusion criterion mentioned above $(n=126)$. This second group consisted of patients who had been treated because of their mental illness either in the Department of Psychiatry ( $\mathrm{n}=90)$ or in the Department of Psychosomatic Medicine ( $\mathrm{n}=36$ ) of the LWL-University Hospital Bochum.

In a further step, the population of all 212 comorbid patients resulting from the selection was assigned to eight different groups based on their additional dermatological diagnosis (Figure 1). This division was made on the basis of the psychodermatological disorder patterns frequently mentioned in the literature. ${ }^{10}$ Subsequently, the patient-related socio-demographic, disease specific and clinical data were transferred to the SPSS file and subjected to further statistical analysis.

Apart from the presence of a mental disorder without a comorbid dermatological disease, no further exclusion criteria were defined. Special care was taken to ensure that two selected collectives did not consist of the cases ("Fall-IDs"), but of the once-allocated patient-IDs that corresponded to each hospital stay in order to avoid duplicates.

The study was approved by the local university ethics committee (Nr: 15-5347) of Ruhr University Bochum, Germany.

\section{Statistical analysis}

Further statistical analyses of the data were performed using IBM SPSS Statistics for Windows, Version 24.0 (IBM Corp., Armonk, NY, USA). Descriptive statistics are given as mean values, standard deviation, and range. Additionally, statistical analyses were performed by appropriate parametric or nonparametric tests. Statistical significance was defined as $\mathrm{p}<$ 0.05 . A value of $p<0.10$ was regarded as a statistical tendency.

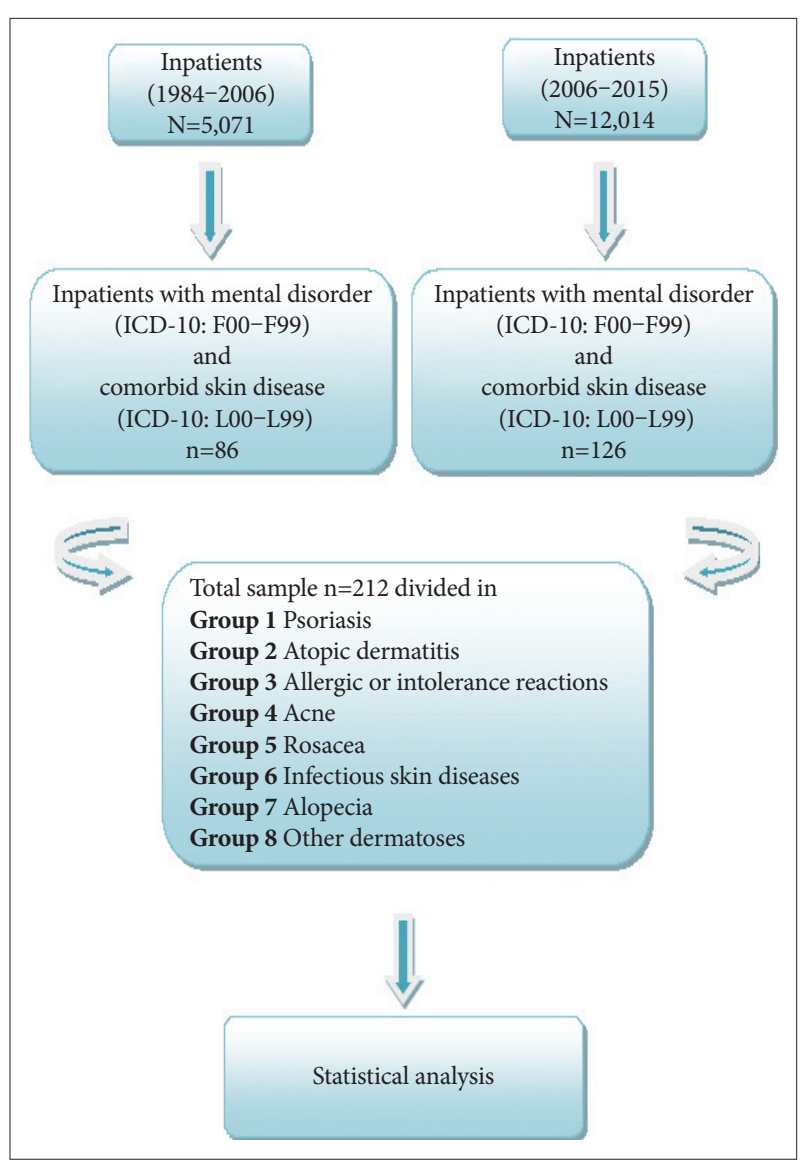

Figure 1. Flow diagram to identify patients groups being comorbid with psychiatric and dermatological disorders.

\section{RESULTS}

The proportion of patients with a primary psychiatric disorder and additional dermatological disease was 1.24\% [212 of 17,085 patients; 116 females (54.7\%) and 96 males (45.3\%); patients had a mean age of $44.38 \pm 16.8$ years].

About half of all comorbid patients (51.9\%) had no permanent partner at the time of their inpatient treatment, 61 patients (28.8\%) were married and 38 (17.9\%) had a solid partnership.

In the majority of the comorbid patients (66\%), we found an overall work impairment conditioned by unemployment ( $\mathrm{n}=$ 78 ) or retirement $(n=62)$. Furthermore, $9.4 \%(n=20)$ of the patient population were students.

\section{Prevalence of psychiatric morbidity}

The primary psychiatric disorders in the studied group are shown in Figure 2. The most common psychiatric diagnoses $(\mathrm{n}=96,45.3 \%)$ were mood disorders according to ICD-10: F30-F39. From these patients, 90 (42.5\%) suffered from depression, more than half of whom $(n=61,63.54 \%)$ had a recurrent depressive disorder (F33.-).

The second largest group $(19.3 \%, \mathrm{n}=41)$ consisted of patients 


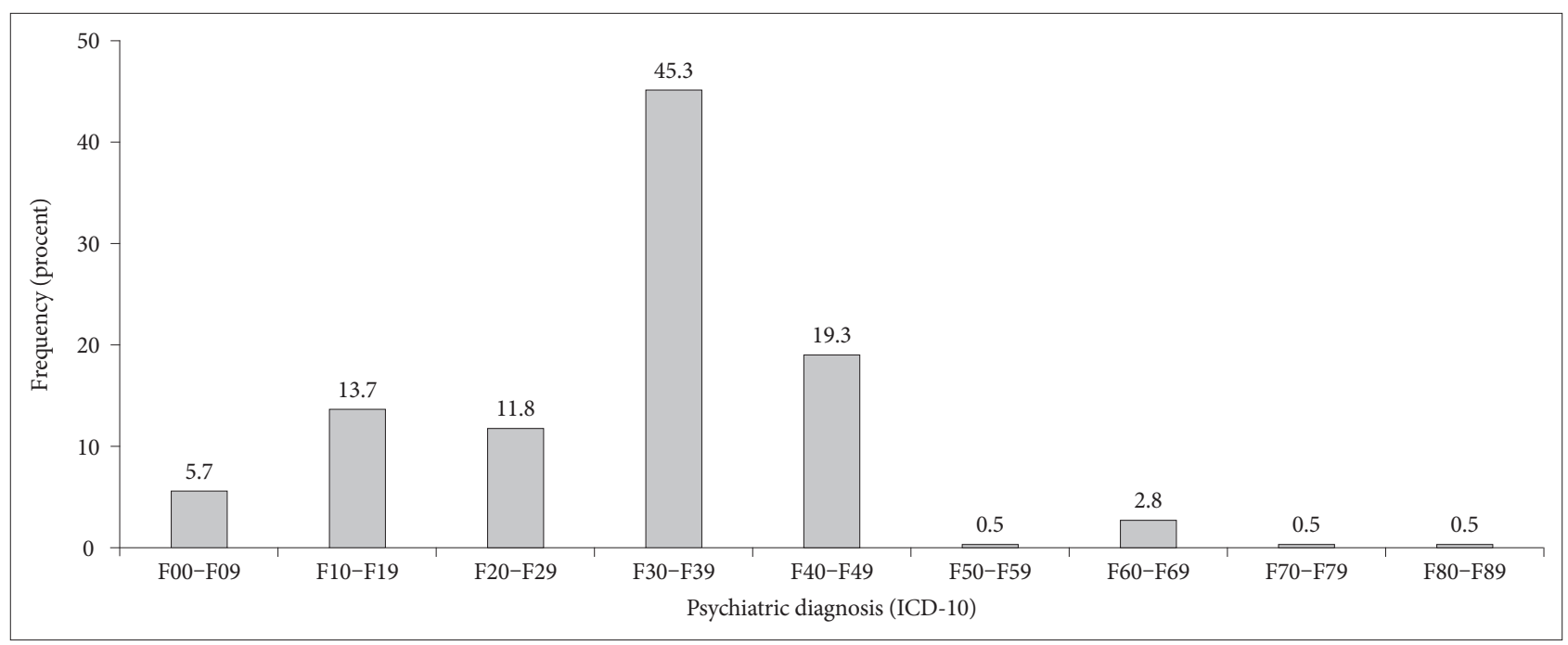

Figure 2. Frequency of psychiatric disorders (ICD-10: F00-F99).

with neurotic, stress-related and somatoform disorders (ICD10: F40-F48). Here, the majority of patients ( $n=21,51.22 \%)$ showed reactions to severe stress and adjustment disorders (ICD-10: F43.-), followed by somatoform disorders (ICD-10: F45.-; $\mathrm{n}=9,21.95 \%$ ).

Moreover, $13.7 \%(n=29)$ of the group suffered from psychoactive drug-induced psychiatric disorders (ICD-10: F10-F19) and so was the third largest, where ethanol was the most common psychoactive substance $(n=26,89.7 \%)$.

Furthermore, $11.8 \%(n=25)$ of the comorbid patients had a disease from the spectrum of schizophrenia, schizotypal and delusional disorders (ICD-10: F20-F29).

The number of patients with an organic delusional disorder, including symptomatic mental disorders (ICD-10: F00-F09), was $n=12$ (5.7\%). Finally, just six patients (2.8\%) had a documented personality and behavioral disorder (ICD-10: F60F69) (Figure 2).

\section{Prevalence of dermatologic morbidity}

See Figure 3 regarding the distribution of common skin diseases among comorbid patients $(n=212)$. The most frequent diagnostic groups were psoriasis $(n=75,35.4 \%)$ and atopic dermatitis ( $\mathrm{n}=48,22.6 \%)$.

\section{Prevalence of comorbidity}

The most frequent comorbid diagnoses were psoriasis with affective disorders $(n=33,15.7 \%)$ and atopic dermatitis with affective disorders ( $n=25,11.8 \%$ ). In detail, 29 of these psoriasis patients had depression and four suffered from a bipolar (manic-depressive) disorder. Of the atopic dermatitis patients, $23 \mathrm{had}$ depression and two suffered from manic-depressive disorder.

Among the infectious-parasitic dermatoses, there was a depression in six patients, dementia in five patients, while

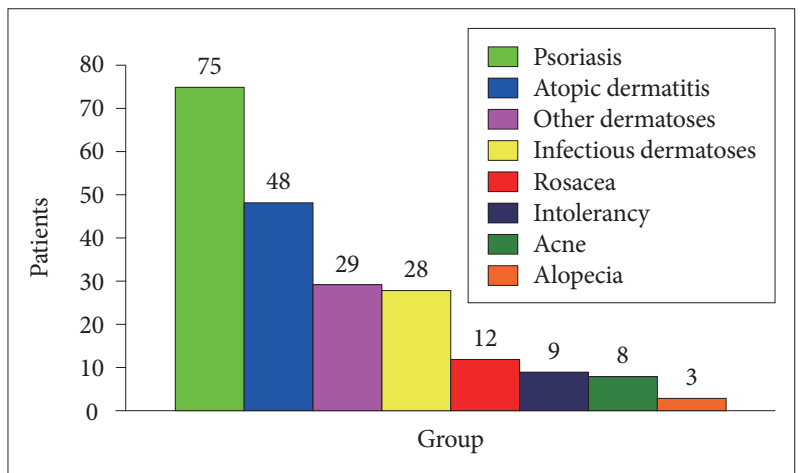

Figure 3. Frequency of dermatological disorders.

four had schizophrenia and three experienced alcoholism. Table 1 illustrates the frequency of the comorbid infectiousparasitic skin diseases in more detail.

\section{Comorbidity and somatic factors}

It should be emphasized that in addition to the psychiatric and dermatological diseases, $30 \%(n=68)$ of our total comorbid collective also had cardiovascular diseases (especially arterial hypertension) and, moreover, diabetic metabolic states. Of the patients with infectious-parasitic skin diseases, more than half (53.6\%) had an additional somatic disease.

\section{DISCUSSION}

In the present retrospective, naturalistic data-based study of more than 17,000 mentally ill inpatients, we found a 1.24\% period prevalence for the comorbid occurrence of psychiatric disorders and skin diseases. Our findings contrast with the findings of previous studies, which found comorbidity rates between $10 \%$ and $60 \%{ }^{1,2,4,7}$ However, it has to be taken into account that these prevalence rates were published almost ex- 
Table 1. Frequency and type of infectious-parasitic dermatoses in mentally ill patients

\begin{tabular}{|c|c|c|c|c|}
\hline $\begin{array}{c}\text { Total } \\
\text { sample }\end{array}$ & $\begin{array}{c}\text { Bacterial } \\
\mathrm{n}=12(42.9 \%)\end{array}$ & $\begin{array}{c}\text { Viral } \\
\mathrm{n}=4(14.3 \%)\end{array}$ & $\begin{array}{c}\text { Funcal } \\
\mathrm{n}=11(39.3 \%)\end{array}$ & $\begin{array}{c}\text { Parasitic } \\
\mathrm{n}=1(3.6 \%)\end{array}$ \\
\hline \multirow[t]{3}{*}{ Subforms } & $\begin{array}{l}\text { Erysipel: } \mathrm{n}=9 \\
\text { (pathogens: } \beta \text {-hämolytic } \\
\text { streptococcus of the Group A }\end{array}$ & $\begin{array}{l}\text { Herpes Zoster: } \mathrm{n}=2 \\
\text { (pathogens: Varizellen-Zoster-Virus) }\end{array}$ & $\begin{array}{l}\text { Candidosis } \\
\text { - Intertriginous: } \mathrm{n}=3 \\
\text { - Cutan+oral mucosa: } \mathrm{n}=3 \\
\text { (pathogens: Yeast Candida albicans) }\end{array}$ & $\begin{array}{l}\text { Scabiosis: } \mathrm{n}=1 \\
\text { (pathogens: Mites) }\end{array}$ \\
\hline & $\begin{array}{l}\text { Phlegmone: } \mathrm{n}=2 \\
\text { (pathogens: Streptococci/ } \\
\text { staphylococci) }\end{array}$ & $\begin{array}{l}\text { Herpes oralis: } \mathrm{n}=1 \\
\text { (pathogens: Herpes-simplex Virus) }\end{array}$ & $\begin{array}{l}\text { Tinea } \\
\text { - Pedis: } \mathrm{n}=2 \\
\text { - Manuum+pedum: } \mathrm{n}=2 \\
\text { (pathogens: Trichophyton or } \\
\text { Microsporum) }\end{array}$ & \\
\hline & $\begin{array}{l}\text { Pyodermia: } \mathrm{n}=1 \\
\text { (pathogens: } \text { ß-hämolytic } \\
\text { streptococci, staphylococcus } \\
\text { aureus) }\end{array}$ & $\begin{array}{l}\text { Condylomata } \\
\text { acuminata: } \mathrm{n}=1 \\
\text { (pathogens: Papillomavirus) }\end{array}$ & $\begin{array}{l}\text { Pityriasis versicolor: } \mathrm{n}=1 \\
\text { (pathogens: Yeast Malassezia furfur) }\end{array}$ & \\
\hline
\end{tabular}

clusively in studies from dermatological clinics. On the other hand, so far only a few studies have been published from psychiatric or psychosomatic treatment facilities, ${ }^{8,9}$ but ultimately they do not allow a direct comparison of prevalence rates due to the existence of methodological differences.

Another possible explanation for the different prevalence could be that the patients with psychiatric illnesses and additional skin symptoms, to avoid social taboos and stigmatization, primarily seek dermatological treatment in specialized facilities, ${ }^{11}$ though it is generally assumed that $30 \%$ of primary dermatologically ill patients have an additional mental disorder; ${ }^{12,13}$ this seems to be especially true for psoriasis and atopic dermatitis (neurodermatitis). Our results of prevalence rates of $35.4 \%$ of co-morbid psoriasis and $22.6 \%$ of atopic dermatitis in patients with a mental disorder are consistent with the findings of other studies. ${ }^{7,14-21}$

The same also applies to our findings of the occurrence of psoriasis and depression (15.7\%), as well as atopic dermatitis and depression (11.8\%). These results seem plausible, since psoriasis, atopic dermatitis (about 1-3\%) and depressive disorders (about 10\%) are among the most common chronic/chronic-recurrent skin and mental illnesses. ${ }^{22}$ The prevalence of atopic dermatitis is described as increasing and in childhood even affects between $10 \%$ to $30 \%$ of children. ${ }^{23}$

In addition to genetic disposition and immunological and hormonal processes, certain medications, environmental factors, and psychosocial stressors are critical in the multifactorial etiopathogenesis of both dermatoses. On the one hand, while childhood autoimmune diseases, which include psoriasis, is discussed as caused by stressful childhood experienc$\mathrm{es},{ }^{24}$ on the other hand, the association between atopic dermatitis and mental illness seems to be independent of the burden of serious childhood events. ${ }^{25}$ Again, it is not surpris- ing that the appearance and symptoms of both skin diseases can have a negative effect on mental well-being and quality of life. ${ }^{26,27}$ Despite the prevalence of suicidal thoughts in both psoriasis patients ${ }^{28}$ and patients with atopic dermatitis, ${ }^{23}$ a recent study by Thyssen et al..$^{29}$ has shown that these patients undergo no psychiatric consultation or treatment.

\section{Cardiovascular disease in mentally ill patients with comorbid skin disorders}

Of particular note is the lifetime prevalence of $32.2 \%$ of cardiovascular diseases in psychiatric and psychosomatic patients with comorbid dermatosis. Both mental and dermatological disorders are associated with an increased risk of cardiovascular disease. ${ }^{30-33}$ For example, Topic and colleagues 30 found somatic comorbid diseases to be significantly more common in their controlled study of 76 major depressive patients compared to the healthy control group. Cardiovascular disease was most commonly diagnosed at $46.1 \%$, compared to $13.9 \%$ in the control group. Here, an increase in the C-reactive protein (CRP), an acute-phase protein whose synthesis is increasingly induced after the release of proinflammatory cytokines, was found to be significantly more frequent in the depressive patients than in the control subjects. ${ }^{30}$ An elevated CRP level is again being discussed as a risk factor for atherogenesis and metabolic syndrome with an increased risk of myocardial infarction or cerebral insult. ${ }^{30}$ In this context, it is not surprising that chronic inflammatory skin diseases are also associated with cardiovascular comorbidities, and this relationship should be of prime interest for researchers, especially in the case of patients with psoriasis. ${ }^{33,34}$ Since fatty tissue as an endocrine organ, among other things, forms cytokines, the resulting influence on the skin's immune system and the contribution to the pathogenesis of psoriasis has been discussed. ${ }^{35}$ A large cohort study from Denmark with 
nearly 30,000 people suffering from psoriasis showed that the risk of cardiovascular disease was particularly high in psoriasis patients who also suffered from an acute depressive disorder. ${ }^{36}$

\section{Infectious skin diseases in mentally ill patients}

Compared to the studies of Mookhoeck et al. ${ }^{8}$ and Moftah et al., ${ }^{9}$ which found high comorbidity rates of over $70 \%$ for infectious-parasitic dermatoses and mental disorders in primary psychiatric patients, our rate was significantly lower at $13.2 \%$.

The only commonality between these studies and ours is the frequency of skin mycoses, which, in addition to bacterial infections, was the second leading cause of infectious skin changes in our patients.

This is not surprising since mycoses, especially in the form of tinea manuum and tinea pedis, are very common in the general population with a lifetime prevalence of $6.5^{-14} \%^{37,38}$ and $15-25 \%,{ }^{39}$ respectively.

With regard to psychiatric patient groups, the literature suggests that patients with schizophrenia appear to be particularly susceptible to skin mycosis. ${ }^{40,41}$ This impression could not be confirmed by our investigation, since the proportion of patients suffering from schizophrenia with dermatological comorbidities was generally low, both in the group as a whole and in the group of infectious-parasitic comorbid dermatoses. In our investigation, the strongest bacterial infectious dermatoses affected patients suffering from dementia or another organic brain disease.

This coupled with the finding that half of the patients experienced other cardiovascular risk factors or diseases underscores the importance of somatic comorbidities with consecutive immunodeficiencies as a potential pathogenetic factor for infectious dermatoses. To the best of our knowledge, up-todate data and studies on this topic are not available, so there is a need for further research here. ${ }^{42}$ In summary, the hypothesis that patients with a mental disorder are more likely to develop infectious-parasitic dermatoses cannot be confirmed. On the basis of our naturalistic examination of both inpatient psychiatric and inpatient psychosomatic patients, mentally ill patients do not necessarily suffer from infectious-parasitic dermatoses; however, such dermatoses occurred predominantly in patients with dementia and brain organic syndromes. Finally, our study also confirms the frequent association of psoriasis and neurodermatitis with depressive illness.

\section{Limitations}

There are some limitations of the study. In addition to the retrospective recording, the resulting small case numbers of the individual subgroups of inpatients represent a significant limiting factor with regard to general statements and can not stand for the whole population of psychiatric patients. Equal- ly problematic is the heterogeneity of our study population, which allows only limited representative statements regarding the group of co-morbid patients, especially in the outpatient setting. It should also be taken into account that the data from the inpatients predominantly refers to seriously ill patients.

Moreover, in this retrospective and naturalistic design, not every patient may have reported a comorbid dermatological diagnosis, especially taking into account disease-specific features in dementia or schizophrenia. Furthermore, due to the computer-based search method, we cannot rule out the possibility that we failed to identify all corresponding patients. Therefore, an underestimation of the prevalence of co-morbid dermatological diseases in psychiatric and psychosomatic patients is likely. This is a strong limitation. For example, the difference found between unipolar depression and bipolar disorder found here could represent a selection bias.

Neither the severity of the mental disorder nor the dermatological disease could be validated in this study, further limiting the representativeness of our results.

\section{Conclusions}

The results indicate a link between stress-related dermatoses and mental illness, especially with regard to the clarification of further predisposing factors that contribute to the development of comorbidities in some of the patients. As such, there is a need for further research and future studies could provide important insights into these pathogenic mechanisms and the relevant therapies.

\section{Acknowledgments}

The presented partial results are data from CM’s doctoral dissertation.

\section{Conflicts of Interest}

The authors have no potential conflicts of interest to disclose.

\section{Author Contributions}

Conceptualization: Paraskevi Mavrogiorgou, Georg Juckel. Data curation: Corinna Mersmann, Gabriele Gerlach. Formal analysis: Corinna Mersmann, Paraskevi Mavrogiorgou, Georg Juckel. Funding acquisition: Georg Juckel. Investigation: Corinna Mersmann, Paraskevi Mavrogiorgou, Gabriele Gerlach. Methodology: Corinna Mersmann, Paraskevi Mavrogiorgou. Project administration: Paraskevi Mavrogiorgou, Georg Juckel. Resources: Stephan Herpertz, Georg Juckel. Software: Paraskevi Mavrogiorgou. Supervision: Stephan Herpertz, Georg Juckel. Validation: All authors. Visualization: Corinna Mersmann, Paraskevi Mavrogiorgou. Writingoriginal draft: Corinna Mersmann, Paraskevi Mavrogiorgou. Writing-review \& editing: Corinna Mersmann, Paraskevi Mavrogiorgou, Georg Juckel.

\section{ORCID iDs}

Paraskevi Mavrogiorgou https://orcid.org/0000-0002-9138-0445

Georg Juckel https://orcid.org/0000-0001-9860-9620

\section{REFERENCES}

1. Dalgard FJ, Gieler U, Tomas-Aragones L, Lien L, Poot F, Jemec GBE, et al. The psychological burden of skin diseases: a cross-sectional multi- 
center study among dermatological out patients in 13 European countries. J Invest Dermatol 2015;135:984-991.

2. Picardi A, Abeni D, Melchi CF, Puddu P, Pasquini P. Psychiatric morbidity in dermatological outpatients: an issue to be recognized. Br J Dermatol 2000;143:983-991.

3. Cvetkovski RS, Zachariae R, Jensen H, Olsen J, Johansen JD, Agner T. Quality of life and depression in a population of occupational hand eczema patients. Contact Dermatitis 2006;54:106-111.

4. Kurd SK, Troxel AB, Crits-Christoph, Gelfand JM. The risk of depression, anxiety, and suicidality in patients with psoriasis: a populationbased cohort study. Arch Dermatol 2010;146:891-895.

5. Boehm D, Schmitt-Ott G, Finkeldey F, John SM, Dwinger C, Werfel T, et al. Anxiety, depression and impaired-related quality of life in patients with occupational hand eczema. Contact Dermatitis 2012;67:184-192.

6. Onderdijik AJ, van der Zee HH, Esmann S, Lophaven S, Dufour DN, Jemec GB, et al. Depression in patients with hidradenitis suppurativa. J Eur Acad Dermatol Venereol 2013;27:473-478.

7. Sanna L, Stuart AL, Pasco JA, Jacka FN, Berk M, Maes M, et al. Atopic disorders and depression: findings from a large, population-based study. J Affect Disord 2014;155:261-265.

8. Mookhoeck EJ, Van De Kerkhof PC, Hovens JE, Brouwers JR, Loonen AJ. Skin disorders in chronic psychiatric illness. J Eur Acad Dermatol Venereol 2010;24:1151-1156.

9. Moftah NH, Kamel AM, Attia HM, El-Baz MZ, Abd El-Moty HM. Skin diseases in patients with primary psychiatric conditions: a hospital based study. J Epidemiol Glob Health 2013;3:131-138.

10. Mavrogiorgou P, Juckel G. Dermatologische Erkrankungen und ihre Bedeutung für die Psychiatrie. Nervenarzt 2017;88:254-267.

11. Brown GE, Malakouti M, Sorenson E, Gupta R, Koo JY. Psychodermatology. Adv Psychosom Med 2015;34:123-134.

12. Nowak DA, Wong SM. DSM-5 update in psychodermatology. Skin Therapy Lett 2016;21:4-7.

13. Kuhn H, Mennella C, Magid M, Stamu-O’Brien C, Kroumpouzos G. Psychocutaneous disease: pharmacotherapy and psychotherapy. J Am Acad Dermatol 2017;76:795-808.

14. Koo J, Marangell LB, Nakamura M, Armstrong A, Jeon C, Bhutani T, et al. Depression and suicidality in psoriasis: review of the literature including the cytokine theory of depression. J Eur Acad Dermatol Venereol 2017;31:1999-2009.

15. Petraskiene R, Valiukeviciene S, Macijauskiene J. Associations of the quality of life and psychoemotional state with sociodemographic factors in patients with psoriasis. Medicina (Kaunas) 2016;52:238-243.

16. Bangemann K, Schulz W, Wohlleben J, Weyergraf A, Snitjer I, Werfel T, et al. Depression und Angststörung bei Psoriasispatienten. Hautarzt 2014;65:1056-1061.

17. Dowlatshahi EA, Wakkee M, Arends LR, Nijsten T. The prevalence and odds of depressive symptoms and clinical depression in psoriasis patients: a systematic review and meta-analysis. J Investig Dermatol 2014;134:1542-1551.

18. Dieris-Hirche J, Gieler U, Kupfer J, Milch WE. Suicidal ideation, anxiety and depression in adult patients with atopic dermatitis. Hautarzt 2009;60:641-646.

19. Yu SH, Silverberg JI. Association between atopic dermatitis and depression in US adults. J Invest Dermatol 2015;135:3183-3186.

20. Eckert L, Gupta S, Amand C, Gadkari A, Mahajan P, Gelfand JM. Impact of atopic dermatitis on health related quality of life and productivity in adults in the United States: an analysis using the National Health and Wellness Survey. J Am Acad Dermatol 2017;77:274-279.

21. Lee SH, Lee SH, Lee SY, Lee B, Lee SH, Park YL. Psychological health status and health-related quality of life in adults with atopic dermatitis. A nationwide cross-sectional study in South Korea. Acta Derm Venereol 2018;98:89-97.

22. Nicholas MN, Gooderham M. Psoriasis, depression, and suicidality. Skin Therapy Lett 2017;22:1-4.

23. Dieris-Hirche J, Gieler U, Petrak F, Milch W, Te Wildt B, Dieris B, et al.
Suicidal ideation in adult patients with atopic dermatitis: a German cross-sectional study. Acta Derm Venereol 2017;97:1189-1195.

24. Saxton KB, John-Henderson N, Reid MW, Francis DD. The social environment and IL-6 in rats and humans. Brain Behav Immun 2011;25: 1617-1625.

25. Ajdacic-Gross V, Aleksandrowicz A, Rodgers S, Mutsch M, Tesic A, Müller M, et al. Infectious, atopic and inflammatory diseases, childhood adversities and familial aggregation are independently associated with the risk for mental disorders: results from a large Swiss epidemiological study. World J Psychiatry 2016;6:419-430.

26. Ferreira BR, Da Costa Abreu JL, Dos Reis JP, Figueiredo AM. Psoriasis and associated psychiatric disorders: a systematic review on etiopathogenesis and clinical correlation. J Clin Aesthet Dermatol 2016;9:36-43.

27. Kwak Y, Kim Y. Health-related quality of life and mental health of adults with atopic dermatitis. Arch Psychiatr Nurs 2017;31:516-521.

28. Strober B, Gooderham M, de Jong EMGJ, Kimball AB, Langley RG, Lakdawala N, et al. Depressive symptoms, depression, and the effect of biologic therapy among patients in Psoriasis Longitudinal Assessment and Registry (PSOLAR). J Am Acad Dermatol 2018;78:70-80.

29. Thyssen JP, Hamann CR, Linneberg A, Dantoft TM, Skov L, Gislason $\mathrm{GH}$, et al. Atopic dermatitis is associated with anxiety, depression, and suicidal ideation, but not with psychiatric hospitalization or suicide. Allergy 2018;73:214-220.

30. Topic R, Milicic D, Stimac Z, Loncar M, Velagic V, Marcinko D, et al. Somatic comorbidity, metabolic syndrome, cardiovascular risk, and CRP in patients with recurrent depressive disorders. Croat Med J 2013; 54:453-459.

31. Tully PJ, Baune BT. Comorbid anxiety disorders alter the association between cardiovascular diseases and depression: the German National Health Interview and Examination Survey. Soc Psychiatry Psychiatr Epidemiol 2014;49:683-691.

32. Marshall VD, Moustafa F, Hawkins SD, Balkrishnan R, Feldman SR. Cardiovascular disease outcomes associated with three major inflammatory dermatologic diseases: apropensity-matched case control study. Dermatol Ther (Heidelb) 2016;6:649-658.

33. Hu SC, Lan CE. Psoriasis and cardiovascular comorbidities: focusing on severe vascular events, cardiovascular risk factors and implications for treatment. Int J Mol Sci 2017;18. pii: E2211.

34. Gerdes S, Mrowietz U, Boehncke WH. Comorbidity in psoriasis. Hautarzt 2016;67:438-444.

35. Bai F, Zheng W, Dong Y, Wang J, Garstka MA, Li R, et al. Serum levels of adipokines and cytokines in psoriasis patients: a systematic review and meta-analysis. Oncotarget 2017;9:1266-1278.

36. Egeberg A, Khalid U, Gislason GH, Mallbris L, Skov L, Hansen PR. Impact of depression on risk of myocardial infarction, stroke and cardiovascular death in patients with psoriasis: a Danish nationwide study. Acta Derm Venereol 2016;96:218-221.

37. Gupta AK, Gupta G, Jain HC, Lynde CW, Foley KA, Daigle D, et al. The prevalence of unsuspected onychomycosis and its causative organisms in a multicentre Canadian sample of 30000 patients visiting physicians' offices. J Eur Acad Dermatol Venereol 2016;30:1567-1572.

38. Chagon A, Franca K, Fernandez A, Nouri K. Psychosocial impact of onychomycosis: a review. Int J Dermatol 2013;52:1300-1307.

39. Sakka N, Shemer A, Barzilai A, Farhi R, Daniel R. Occult tinea pedis in an Israeli population and predisposing factors for the acquisition of the disease. Int J Dermatol 2015;54:146-149.

40. Wu BY, Wu BJ, Lee SM, Sun HJ, Chang YT, Lin MW. Prevalence and associated factors of comorbid skin diseases in patients with schizophrenia: a clinical survey and national health database study. Gen Hosp Psychiatry 2014;36:415-421.

41. Kawai M, Suzuki T, Hiruma M, Ikeda S. A retrospective cohort study of tinea pedis and tinea unguium in inpatients in a psychiatric hospital. Med Mycol J 2014;55:E35-E41.

42. Mavrogiorgou P, Juckel G. Erkrankungen der Haut bei primär psychischen Störungen. Fortschr Neurol Psychiatr 2016;84:608-616. 